\title{
Sepsis-Induced Cardiomyopathy: Mechanisms and Treatments
}

\author{
Yan-Cun Liu*t, Mu-Ming Yü, Song-Tao Shou and Yan-Fen Chai* \\ Department of Emergency Medicine, Tianjin Medical University General Hospital, Tianjin, China
}

Sepsis is a lethal syndrome with a high incidence and a weighty economy burden. The pathophysiology of sepsis includes inflammation, immune dysfunction, and dysfunction of coagulation, while sepsis-induced cardiomyopathy $(S / C)$, defined as a global but reversible dysfunction of both sides of the heart induced by sepsis, plays a significant role in all of the aspects above in the pathogenesis of sepsis. The complex pathogenesis of $S / C$ involves a combination of dysregulation of inflammatory mediators, mitochondrial dysfunction, oxidative stress, disorder of calcium regulation, autonomic nervous

OPEN ACCESS

Edited by:

Pietro Ghezzi,

Brighton and Sussex Medical School,

United Kingdom

Reviewed by:

Alain Rudiger,

University Hospital Zurich,

Switzerland

Andrea Morelli,

Sapienza Università di Roma, Italy

*Correspondence:

Yan-Fen Chai

chaiyanfen2012@126.com;

Yan-Cun Liu

yancunliu@tmu.edu.cn

tThese authors have contributed

equally to this work.

Specialty section:

This article was submitted to

Inflammation,

a section of the journal

Frontiers in Immunology

Received: 14 March 2017

Accepted: 08 August 2017

Published: 24 August 2017

Citation:

Liu Y-C, Yu M-M, Shou S-T and

Chai Y-F (2017) Sepsis-Induced

Cardiomyopathy: Mechanisms and

Treatments.

Front. Immunol. 8:1021.

doi: 10.3389/fimmu.2017.01021 system dysregulation, and endothelial dysfunction. The treatments for SIC include the signal pathway intervention, Chinese traditional medicine, and other specific therapy. Here, we reviewed the latest literatures on the mechanisms and treatments of SIC and hope to provide further insights to researchers and create a new road for the therapy of sepsis.

Keywords: sepsis-induced cardiomyopathy, mechanisms, treatments, inflammatory mediators, Chinese traditional medicine

\section{INTRODUCTION}

Sepsis is a lethal syndrome induced by infection, which has a reported annual death of 200,000 in the United States (1). The pathophysiology of sepsis includes inflammation, immune dysfunction, and coagulation disorders. Though studies have confirmed the immunosuppression in the late stage as the leading cause of mortality of septic patients; however, the septic shock in the early onset of sepsis, which induced by cytokine storm and cardiac dysfunction, is also an important cause of death for septic patients, especially for the young patients with toxic shock syndrome or meningococcemia (2).

Heart, as the pump organ, plays a key role in the pathology of septic shock. With the development of tissue Doppler imaging, perfusion echocardiography myocardial, and hemodynamics monitoring (3), the definition of sepsis-induced cardiomyopathy (SIC) has been summarized as a global (systolic and diastolic) but reversible dysfunction of both the left and right sides of the heart, which is induced by myocardial depressants released from pathogen and host, and global ischemia after peripheral vasodilation, arterial and capillary shunting in septic distributive shock (4). A retrospective cohort study reported that SIC developed in $13.8 \%$ of patients with sepsis and septic shock (5), which could be used as an outcome predictor in the septic patients (6). The mechanisms of SIC includes the

\footnotetext{
Abbreviations: SIC, sepsis-induced cardiomyopathy; TDI, tissue Doppler imaging; PAMPs, pathogen-associated molecular patterns; TLR, toll-like receptor; TNF, tumor necrosis factor; IL, interleukin; LVEF, left ventricular ejection fraction; HSPs, heat shock proteins; CLP, cecal ligation and puncture; HMGB, high-mobility group protein B; NO, nitric oxide; NOS, nitric oxide synthese; DAMPs, damage-associated molecular patterns; VCAM-1, vascular cell adhesion molecule 1; ICAM, intercellular adhesion molecule; PPAR, peroxisome proliferator-activated receptor; NRG-1, neuregulin-1; TCM, Traditional Chinese medicine; XBJ, Xuebijing injection; EPO, erythropoietin; miRNAs, microRNAs.
} 
preload deficiency during distributive shock, heart-lung interactions during mechanical ventilation, and ventricular-arterial coupling in the presence of vasopressors (7); however, here, we focus on the mechanisms of cardiomyocyte dysfunction and treatments of SIC and hope to provide further insights for the management of SIC.

\section{THE MECHANISMS OF SIC}

\section{Pathogen-Associated Molecular Patterns (PAMPs)}

Pathogen-associated molecular patterns released by infecting organisms not only bind immune receptors on inflammatory cells but also bind receptors on cells in the heart (8). Endotoxin is released by the lysis of Gram-negative bacteria. A research from healthy volunteers showed that there was a reduction in left ventricular ejection fraction (LVEF) and LV performance after the injection of endotoxin (9). The endotoxin-induced myocardial dysfunction probably depends on the toll-like receptor (TLR) 4-induced cytokines release as a delay in onset of myocardial depression after endotoxin administration (10). Circulating Pneumolysin, another common PAMP produced by Streptococcus pneumoniae, induced cardiomyocyte injury through triggering profound calcium influx during pneumococcal infection (11).

\section{Toll-Like Receptors}

Toll-like receptors are transmembrane glycoproteins, which recognize many PAMPs with extracellular domains and aggravate the exaggerated inflammatory response to bacterial infection through activating nuclear factor (NF) $\kappa \mathrm{B}$ (12). TLR4 is the most studied member in the SIC study among the TLRs family. A research from TLR4-deficient mice confirmed the essential role of TLR4 in mediating neutrophil migratory phagocytic functions, attenuating inflammation, reducing reactive oxygen species generation, and enhancing bacterial clearance (13). Other TLR-related genes (TLR2, 3, and 9) were demonstrated to be involved in sepsis-induced cardiac dysfunction from recent studies. TLR2 increased the myocardium and serum cardiodepressant cytokines level and weakened the neutrophil migratory function, which sharpened the SIC (14). TLR3 played a deleterious role in mediating cardiac dysfunction in sepsis by increasing cecal ligation and puncture (CLP)-induced cardiomyocytes apoptosis and Fas and Fas ligand expression in the myocardium (15). CpG oligodeoxynucleotide, the TLR9 ligand, through activating both phosphoinositide 3 kinase/Akt and extracellular signal-related kinase signaling, attenuated cardiac dysfunction in polymicrobial sepsis (16). However, a recent research demonstrated that eritoran, an anti-TLR4 to terminate MD2/TLR4-mediated signaling, did not significantly improve outcome for patients with severe sepsis and septic shock (17). Additional studies are needed to explain the detailed mechanisms of SIC regulated by TLRs.

\section{Cytokines}

The main inflammatory mediators that might contribute to SIC are tumor necrosis factor (TNF)- $\alpha$, interleukin (IL)-1, and IL-6. In 1992, Eichenholz et al. demonstrated that TNF- $\alpha$ in plasma had a dose-dependent relationship with the depression of LVEF from a canine model of septic shock (18). At the same year, Vincent et al. showed that the administration of murine monoclonal antiTNF antibodies could transiently improve ventricular function in patients with septic shock (19). IL-1, cooperated with TNF- $\alpha$, decreased the myocardial contractility, and played an active role in septic myocardial dysfunction. In a recent study from children with meningococcal septic shock (20), Pathan et al. confirmed the negative inotropic effects created by IL-6 via a p38 mitogenactivated protein kinase pathway and suggested a novel therapy to reverse myocardial dysfunction. However, as the half-lives of TNF- $\alpha$, IL-1, and IL- 6 are less than $6 \mathrm{~h}$, it seemed that these cytokines did not induce SIC independently, and the detailed mechanisms still need further investigations.

\section{Damage-Associated Molecular Patterns (DAMPs) \\ Extracellular Histones}

Circulating extracellular histones in plasma have been detected in septic patients, and it interacts with TLR 2 and TLR4 on a variety of different cell types and contributes to endothelial dysfunction, organ failure, and death in experimental sepsis $(21,22)$. A recent study showed that high levels of histones in plasma were significantly associated with cardiac injury and dysfunction in septic patients and high level of histones predicted a worse outcome (23), and another study from septic mice demonstrated that neutralizing histones antibodies or drugs, which block histones interactions with cardiomyocytes might represent an effective strategy to prevent or ameliorate SIC (24). However, it is unclear that whether the histones in plasma are the cause or the result of SIC as histones occur inside the nucleus and can be released into circulation because of cytokines storm and cellular death during sepsis. Further researches are needed to confirm the exactly roles played by histones in the pathogenesis of SIC.

\section{Heat Shock Proteins (HSPs)}

Heat shock proteins, a group of highly selective proteins produced by cells in reaction to stress, appear to play a critical role in the development of thermotolerance and protection from cellular damage associated with stresses (25). Early research has shown that HSP72 can reverse the cardiac dysfunction of septic model induced by CLP (26). Some researches subsequently unveiled that HSP20-attenuated endotoxin-induced myocardial dysfunction and apoptosis via inhibition of NF- $\mathrm{BB}$ activation (27), while HSPA12B reduced the leukocytes infiltration into the myocardium and prevented SIC through preserving activation of PI3K/ Akt signaling (28). Later, Hsu et al. confirmed that exogenous HSC70 pretreatment attenuated LPS-induced myocardial dysfunction in septic rats (29). The detailed protective mechanisms of HSPs in sepsis still require further studies.

\section{High-Mobility Group Protein B (HMGB)1}

High-mobility group protein B1, a non-histone nuclear protein, serves as an alarmin to drive the pathogenesis of inflammatory and autoimmune disease (30). The serum level of HMGB1 in septic patients induced by severely burn is significantly increasing, and it is associated with the fatal outcome of sepsis (31). 
$\mathrm{Xu}$ et al. demonstrated that HMGB1 could also be produced by viable cardiomyocytes in septic mice, and it mediated the LPSinduced myocardial dysfunction through a TLR4/PI3K $\gamma$ signaling pathway (32). Zhang et al. showed that HMGB1 enhanced sarcoplasmic reticulum $\mathrm{Ca}^{2+}$ leak through TLR4-reactive oxygen species signaling pathway, and decreased systolic $\mathrm{Ca}^{2+}$ transient and cardiomyocytes contractility, both contribute to the mechanisms underlying the HMGB1-induced SIC (33).

\section{Nitric Oxide (NO)}

Nitric oxide, a small and highly reactive molecule with a halflife of a few seconds, is produced from all types of cardiac cells and has a multitude of cardiovascular effects in cardiovascular homeostasis. NO is produced from nitric oxide synthese (NOS), which exists in two forms: constitutive (NOS1, NOS3) and inducible (NOS2). NOS1 and NOS3 relevantly contribute to bioactive NO pool (34) and culprit in early septic myocardial depression, whereas NOS2 may mediate myocardial depression that occurs in late sepsis (35). The mechanisms of NO-induced SIC include vasodilatation with resulting changes in preload, afterload, and cardiac perfusion, downregulating $\beta$-adrenergic receptors (36), depression of mitochondrial respiration, and further release of pro-inflammatory cytokines (37). Another adverse effect of NO on myocardial depression is the peroxynitrite, produced by NO metabolism, which interacts with lipids, DNA, and proteins (38) and affects the function of mitochondrial permeability transition pores, with subsequent mitochondrial dysfunction (39). Removal of peroxynitrate improved the myocardial performance in the study of cytokine-induced myocardial depression (40).

\section{Mitochondrial Dysfunction and Oxidative Stress}

Mitochondrial dysfunction plays a significant role in the pathogenesis of sepsis and the degree of mitochondrial dysfunction is correlated with outcomes. Cardiomyocytes demonstrate mitochondrial ultrastructural damage in both septic animals and patients (41). Studies have shown that non-competitive inhibition of cytochrome $\mathrm{C}$ oxidase developed during sepsis, which interrupted the inhibition of oxidative phosphorylation and decreased production of ATP, leading to sepsis-associated myocardial depression (42). Low T3 syndrome, a very common phenomenon in septic patients, could also induce the mitochondrial dysfunction and sharpen the myocardial depression (43). When mitochondrial dysfunction persisted, ROS were generated in cardiomyocytes from septic heart, while oxidative stress induced by ROS mediated mitochondrial damage, which accelerated the mitochondrial dysfunction (44). The administration of superoxide scavenger compounds (44) and the inhibition of mitochondrial dysfunction (45) have been shown to prevent mitochondrial abnormalities and improve cardiac function and reduce mortality.

\section{Disorders of Calcium Regulation}

In the normal state, extracellular calcium enters the cardiomyocytes via L-type channels and releases intracellular calcium from sarcoplasmic reticulum, which binds to troponin and activates the contraction proceeds with ATP hydrolysis (46). In the complex situation of SIC, the density of calcium L-type channels decreased, calcium sequestration is in disorder as the phosphorylation of phospholamban is in turbulence, and myofilament calcium sensitivity and responsiveness of the ryanodine receptor to calcium reduced (47). Furthermore, DAMPs, like HMGB-1, enhances SR calcium leak through the TLR4-ROS signaling pathway, then calcium transients and cardiomyocytes contractility decreased. Hence, inhibiting TLR4 or using antioxidant prevents the enhancement of the SR calcium leak, resulting in alleviating myocardial dysfunction (48).

\section{Autonomic Nervous System Dysregulation}

Autonomic dysregulation, which includes resistance to catecholamines and the loss of heart rate variability in septic state plays a significant role in the sepsis-induced cardiac depression. Some studies have demonstrated that septic animal performance a state of catecholamines resistance, which was mediated by the decreased density of myocardial adrenoceptors, the increased expression of inhibitory G-protein, and the disrupted signal transduction (49), despite elevated circulating levels of catecholamines. Hoyer et al. (50) confirmed that the loss of heart rate variability indicated a high probability of progression to multiple organs failure with poor outcomes. When sepsis occurred, apoptosis of neuronal and glial within cardiac autonomic centers increased (51), sepsis-induced uncoupling of the sinoatrial node from cholinergic neural control (52), and the direct current blockade of the sinoatrial node by the elevated cytokines of plasma (53), all contributed to the loss of heart rate variability (Figure 1).

\section{Endothelial Dysfunction}

Sepsis induces the endothelial abnormalities, which is another important aspect that leading to SIC. Endothelial cells secrete more adhesion molecules, which assist injurious neutrophilic infiltration to cardiomyocytes and increase the leukocyte-endothelium interaction in response to inflammatory cytokines in sepsis (54). Vascular cell adhesion molecule 1 (VCAM-1), as the most common example, has been demonstrated in the coronary endothelium and cardiomyocytes of murine models of septic shock. Blockade of VCAM-1 abrogates neutrophil accumulation and prevents the cardiac dysfunction in sepsis (55). Calpain is over activated in cardiac tissue in the setting of sepsis, and the inhibition of Calpain decreases the leukocyte-endothelium interaction and improves sepsis-induced cardiac dysfunction (56). Both of them suggest that VCAM-1 and Calpain may serve as therapeutic targets for SIC. Physical disruption of endothelial cells is another mechanism for the SIC. The injured endothelial cells secrete intercellular adhesion molecule, E-selectin, and thrombomodulin, which lead to the failure of vascular relaxation and are prognostically related to cardiac systolic and diastolic dysfunction (57).

\section{THE TREATMENTS OF SIC}

\section{Hemodynamic Stabilization}

When septic shock occurs, PAMPs, DAMPs, oxidative stress, mitochondrial dysfunction, disorders of calcium regulation, autonomic nervous system dysregulation, and endothelial 


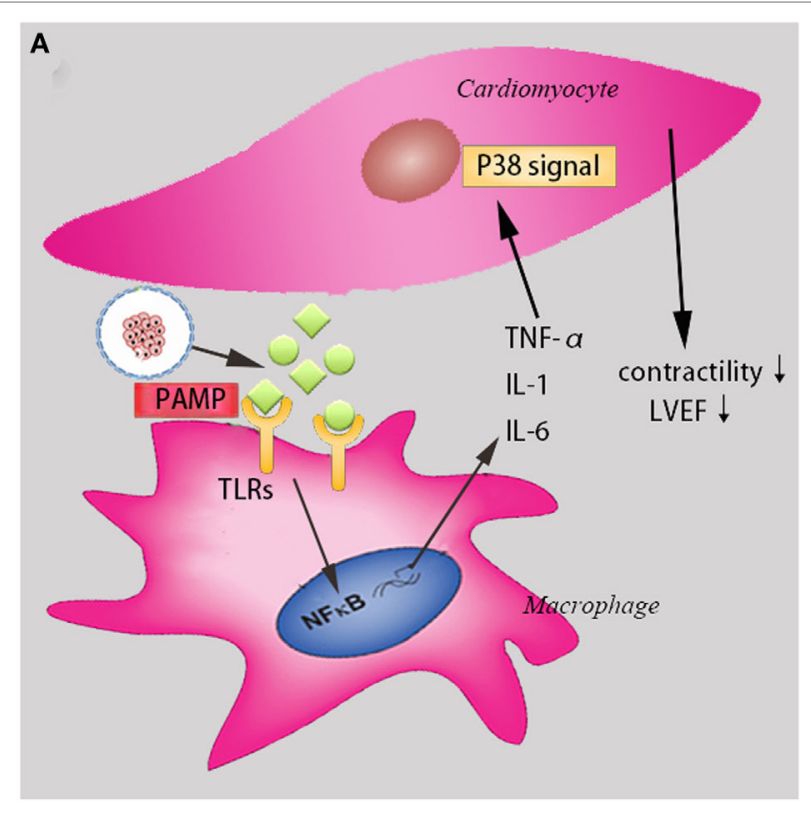

C

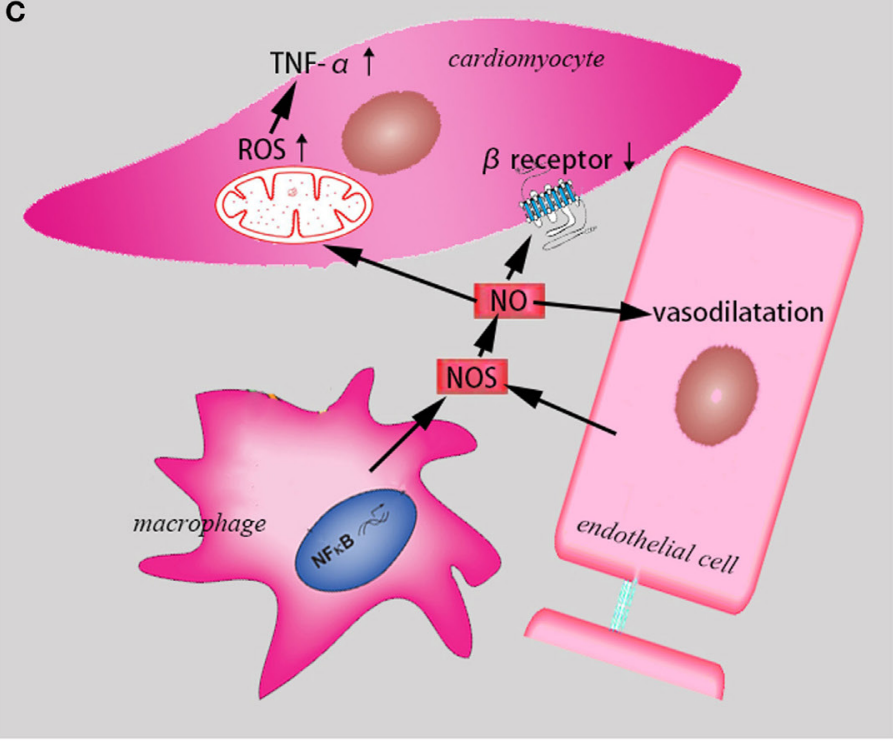

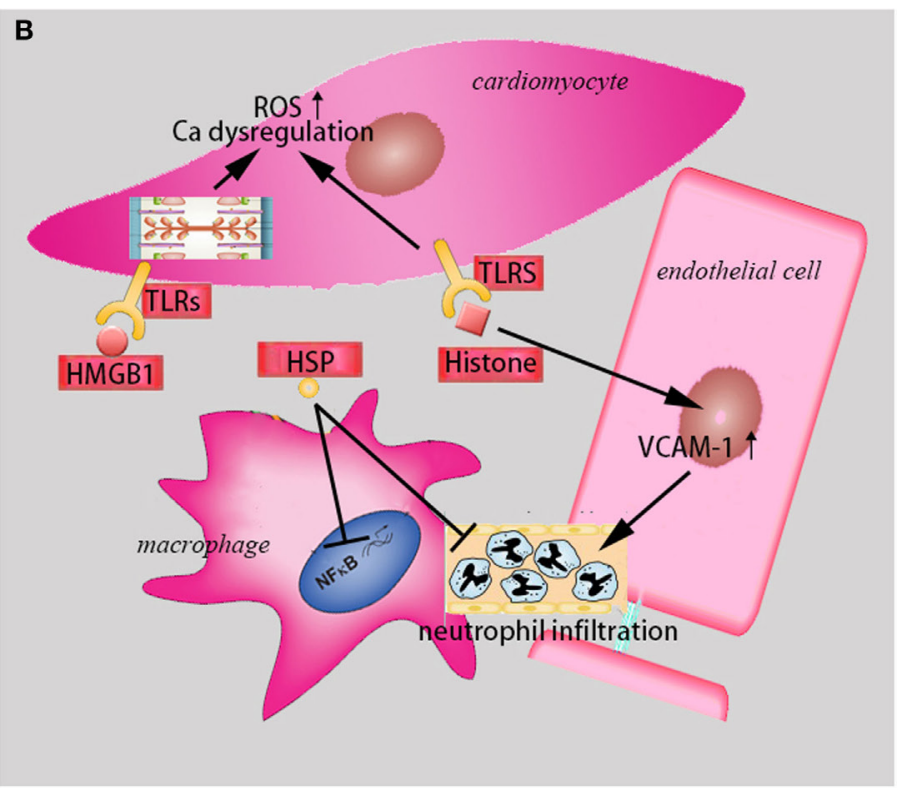

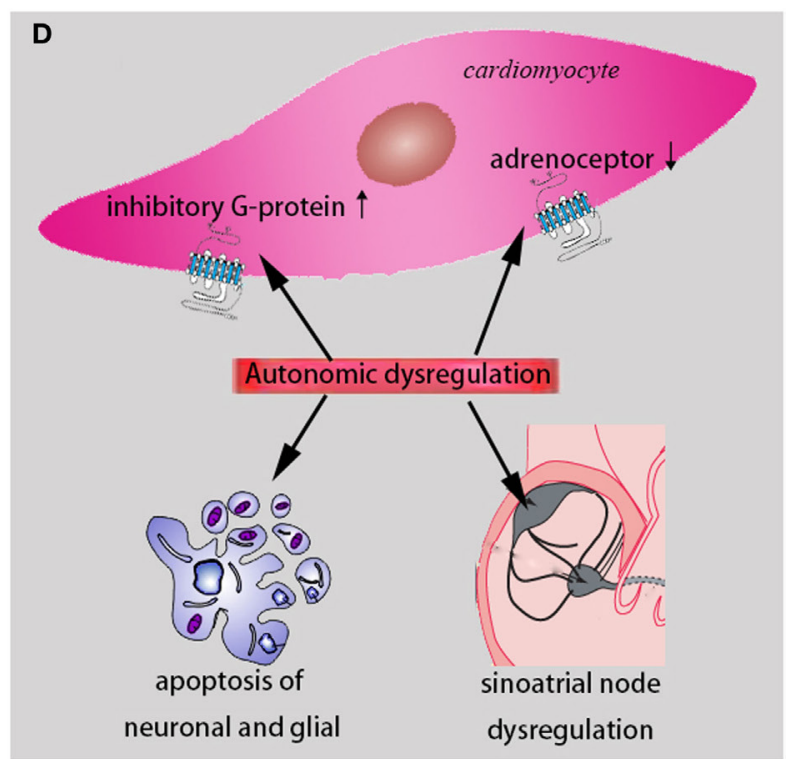

FIGURE 1 | The mechanisms in the sepsis-induced cardiomyopathy. (A) PAMPs and cytokines (TNF- $\alpha$, IL-1, and IL-6) contribute to sepsis-induced cardiomyopathy (SIC). (B) Damage-associated molecular patterns (HMGB1, HSP, and histone) induce SIC through different mechanisms. (C) NO and NOS are involved in SIC. (D) Autonomic dysregulation play a significant role in SIC. PAMP, pathogen-associated molecular pattern. TNF- $\alpha$, tumor necrosis factor- $\alpha$. IL-1, interleukin-1. IL-6, interleukin-6. TLRs, toll-like receptors. NF-кB, nuclear factor-kB. LVEF, left ventricular ejection fraction. HMGB1, high mobility group protein B1. HSP, heat shock protein. ROS, reactive oxygen species. VCAM, vascular cell adhesion molecule. NO, nitric oxide. NOS, nitric oxide syntheses.

dysfunction all contribute to the pathogenesis of SIC. On the other hand, the consequence of SIC is an insufficient supply of oxygen to meet tissue demand, which causes global tissue hypoxia and accelerates the process of septic shock (58). Thus, focusing on hemodynamic stabilization is the foremost step in patients with SIC apart from the proper management of infection.

Rapid and effective fluid therapy guided by monitoring fluid response parameters to remedy hypovolemia is recommended as the cornerstone of sepsis treatments (58). Crystalloids is recommended as the initial fluid in the resuscitation of sepsis; however, a research from septic animal demonstrated that albumin and hypertonic saline were more beneficial on cardiac function compared with normal saline (59).

Inotropic drugs are suggested for the septic patients with low cardiac output after optimization of fluid therapy. Norepinephrine is the first choice from the current guidance, while dobutamine and dopamine are only used in highly selected patients. The use of dopamine was associated with a greater number of adverse events (60). Levosimendan, a calcium-sensitizing drug, sensitizes troponin $\mathrm{C}$ to calcium and enhances the effects of calcium on 
myofilaments during contraction. Different with dobutamine and dopamine, levosimendan does not stimulate $\beta$-adrenergic receptor and cause adverse effects. Studies have shown that levosimendan could preserve septic heart function through cooling down the oxidative burst of circulating cells and inhibiting the release of reactive oxygen species (61). However, a recently randomized clinical trial showed that the addition of levosimendan in adult with sepsis was not associated with lower mortality, and it decreased the probability of successful weaning from mechanical ventilation and increased the risk of supraventricular tachyarrhythmia (62).

\section{Signaling Pathways Intervention}

Multiple signaling pathways are involved in the pathogenesis of SIC, and therapies of targeting signaling pathways have been researched always. Annexin A5, a 35-kDa phospholipid binding protein, decreases cytokine expression and improves cardiac function during endotoxemia treatment through inhibiting LPS binding to TLR4 and leading to reductions in mitogen-activated protein kinase and Akt signaling (63). Peroxisome proliferatoractivated receptor (PPAR), a nuclear receptor, regulates cardiac fatty acid oxidation. Drosatos et al. demonstrated that activation of PPAR $\gamma$ prevented cardiac dysfunction and mortality in spite of development of cardiac inflammation and downregulation of PPAR $\alpha$ in LPS-treated mice (64). Neuregulin-1 (NRG-1), a member of the family of epidermal growth factors, improved cardiac function and protected cardiomyocytes of rats from sepsis via the activation of NRG-1/ErbB signaling axis (65). However, there are some difficulties present in this treatment strategy. First, almost all attempts from signaling pathways intervention are researched from animal models. Second, a single pathway possesses a lot of biological activities. Third, the related pathways influence each other through a complex network of regulatory interactions. All these difficulties remind us the therapy to SIC from signaling pathways intervention still have a long way to go.

\section{Traditional Chinese Medicine (TCM)}

Traditional Chinese medicine has been used for treatment of sepsis in China for many years, and some of them have been confirmed to have beneficial effects for the SIC. Paeoniflorin, one of the major bioactive components of paeony root, attenuates cardiac dysfunction in septic mice via the inhibition of NF- $\mathrm{KB}$
(66). The salutary effects of resveratrol rescue animals from SIC through reversing sepsis-dependent downregulation of PPAR $\gamma$ co-activator $1 \alpha$, and preserving mitochondrial integrity (67). Xuebijing injection (XBJ) is a complex traditional prescription, which is extracted from several herbs with immune modulating functions. XBJ has a significant efficacy in the therapy of sepsis through promoting septic macrophage polarization (68), which has the potential effect in regulating cardiac function in sepsis. With the quick development of pharmaceutical analysis, more and more TCM were analyzed and the detailed mechanisms were gradually revealed, which has a great potential for the researches of SIC.

\section{Others}

$\beta$-adrenoreceptor antagonist has been rarely used in the treatment of patients with septic shock as the existence of SIC. It will potentially decrease the blood pressure, perform negative inotropic effects, and cause pump failure in the already depressed heart. Recently, with the mechanisms of pathological catecholamine excess in SIC was revealed, increasing experimental evidences have suggested that $\beta$-adrenergic regulation may improve cardiac function during septic shock (69). The use of esmolol was associated with reduction of heart rates, and no increased adverse events in septic shock patients (70). Adjunction of selective $\beta 1$-blockade enhances intrinsic cardiac contractility and vascular responsiveness to catecholamine through anti-inflammatory, lowers heart rate for better ventricular filling during diastole, and performs cardiac protective effects in septic animals (71). However, more large clinical trials with different risk subsets and timing of administration are needed to confirm its effects.

Erythropoietin (EPO) is widely used for the treatment of anemia in patients, especially the anemia in patients with chronic kidney disease. The administration of EPO attenuated the impaired systolic contractility in experimental sepsis via activation of the $\beta$-common receptor (72). As the complex and strong interaction between EPO and $\beta c R$ (73), selectively activating the tissue-protective $\beta c \mathrm{R}$-EpoR heterocomplex represents a new therapeutic approach to SIC.

microRNAs (miRNAs) are a class of small 21-23 nucleotides long RNAs molecules, which have been identified as novel regulators of gene expression at the posttranscriptional level.

TABLE 1 | Treatments, mechanisms, and types of study of sepsis-induced cardiomyopathy.

\begin{tabular}{|c|c|c|c|c|c|}
\hline Treatments & Mechanisms & Study type & Details of sepsis & No. of sepsis/total (\%) & Reference \\
\hline Levosimendan & $\begin{array}{l}\text { Calcium-sensitizing, inhibiting reactive oxygen } \\
\text { species }\end{array}$ & $\begin{array}{l}\text { Critically ill } \\
\text { patients }\end{array}$ & Clinical diagnosis of sepsis & $9 / 25(36)$ & (59) \\
\hline Annexin A5 & $\begin{array}{l}\text { Binding to TLR4, mitogen-activated protein } \\
\text { kinase and Akt signaling } \downarrow\end{array}$ & Animal & Intraperitoneal endotoxin & $52 / 103(50)$ & (63) \\
\hline $\begin{array}{l}\text { Peroxisome proliferator- } \\
\text { activated receptor (PPAR) } \gamma\end{array}$ & Activation of PPAR $\gamma$ & Animal & Intraperitoneal endotoxin & $14 / 28(50)$ & $(64)$ \\
\hline Neuregulin-1 (NRG-1) & NRG-1/ErbB $\uparrow$ & Animal & Cecal ligation and puncture (CLP) & $22 / 27(81)$ & (65) \\
\hline Paeoniflorin & $N F-\kappa B \downarrow$ & Animal & intraperitoneal endotoxin & $24 / 48(50)$ & (66) \\
\hline Selective $\beta 1$-blockade & $N F-\kappa B \downarrow$ & Animal & CLP & $18 / 24(75)$ & (71) \\
\hline EPO & $\beta$-common receptor activation & Animal & Intraperitoneal endotoxin, CLP & $112 / 153(73)$ & $(72)$ \\
\hline miR-146a & $N F-\kappa B \downarrow$ & Animal & CLP & $12 / 24(50)$ & (75) \\
\hline miR-21-3p & Regulating SH3 domain-containing protein 2 & Animal & Intraperitoneal endotoxin & $12 / 24(50)$ & $(76)$ \\
\hline
\end{tabular}


miRNAs play strong regulatory effect in almost all cardiovascular processes, like myocardial infarction and heart failure phases (74). Recent studies have shown that miRNAs played a critical role in sepsis-induced cardiac dysfunction. Gao et al. used lentivirus-expressing miR-146a to transfect before subjecting to CLP and results showed that miR-146a attenuated SIC by preventing sepsis-induced NF- $\kappa \mathrm{B}$ activity, attenuating inflammatory cytokine production and decreasing sepsis-induced neutrophils infiltration and macrophages into the myocardium (75). Wang et al. used LPS to induce SIC and provided strong evidence that miR-21-3p controlled SIC via regulating $\mathrm{SH} 3$ domain-containing protein 2 and inhibition of miR-21-3p might be a potential strategy to treat SIC (76). It can be seen that miRNAs-targeting therapy might open a new era for the treatment of SIC (Table 1).

\section{CONCLUSION AND PERSPECTIVE}

Sepsis-induced cardiomyopathy has been defined as a global but reversible dysfunction of heart, and it has been always the topic of intensive research for last four decades. The complex pathogenesis of SIC involves a combination of dysregulation of inflammatory mediators, mitochondrial dysfunction and oxidative stress, disorder of calcium regulation, autonomic nervous system dysregulation, and endothelial dysfunction. Although much progress has been made in the therapies of SIC, like signaling

\section{REFERENCES}

1. Deutschman CS, Tracey KJ. Sepsis: current dogma and new perspectives. Immunity (2014) 40(4):463-75. doi:10.1016/j.immuni.2014.04.001

2. Hotchkiss RS, Monneret G, Payen D. Sepsis-induced immunosuppression: from cellular dysfunctions to immunotherapy. Nat Rev Immunol (2013) 13(12):862-74. doi:10.1038/nri3552

3. De Backer D, Scolletta S. Clinical management of the cardiovascular failure in sepsis. Curr Vasc Pharmacol (2013) 11(2):222-42. doi:10.2174/157016111 1311020011

4. Antonucci E, Fiaccadori E, Donadello K, Taccone FS, Franchi F, Scolletta S. Myocardial depression in sepsis: from pathogenesis to clinical manifestations and treatment. J Crit Care (2014) 29(4):500-11. doi:10.1016/j.jcrc. 2014.03.028

5. Sato R, Kuriyama A, Takada T, Nasu M, Luthe SK. Prevalence and risk factors of sepsis-induced cardiomyopathy: a retrospective cohort study. Medicine (Baltimore) (2016) 95(39):e5031. doi:10.1097/MD.000000000 0005031

6. Micek ST, McEvoy C, McKenzie M, Hampton N, Doherty JA, Kollef MH. Fluid balance and cardiac function in septic shock as predictors of hospital mortality. Crit Care (2013) 17(5):R246. doi:10.1186/cc13072

7. Rudiger A, Singer M. The heart in sepsis: from basic mechanisms to clinical management. Curr Vasc Pharmacol (2013) 11(2):187-95. doi:10.2174/157016113805290227

8. Boyd JH, Mathur S, Wang Y, Bateman RM, Walley KR. Toll-like receptor stimulation in cardiomyoctes decreases contractility and initiates an NF-kappaB dependent inflammatory response. Cardiovasc Res (2006) 72(3):384-93. doi:10.1016/j.cardiores.2006.09.011

9. Suffredini AF, Fromm RE, Parker MM, Brenner M, Kovacs JA, Wesley RA, et al. The cardiovascular response of normal humans to the administration of endotoxin. N Engl J Med (1989) 321(5):280-7. doi:10.1056/ NEJM198908033210503

10. Tavener SA, Kubes P. Is there a role for cardiomyocyte toll-like receptor 4 in endotoxemia? Trends Cardiovasc Med (2005) 15(5):153-7. doi:10.1016/j. tcm.2005.06.001 pathways intervention, TCM, $\beta$-adrenoreceptor antagonist, EPO, and microRNA, there is still no efficient treatment in patients with SIC.

\section{ETHICS STATEMENT}

The study was approved by the ethics committees at the Tianjin Medical University General Hospital, Tianjin, China.

\section{AUTHOR CONTRIBUTIONS}

Y-CL and M-MY drafted the manuscript and performed a literature review. S-TS and Y-FC were served as chief physicians. All authors read and approved the final manuscript.

\section{ACKNOWLEDGMENTS}

We thank professor Shu-Zhang Cui of Emergency Department of Tianjin Medical University General Hospital for the guidance of case presentation.

\section{FUNDING}

This study was supported by grants from the National Natural Science Foundation (No. 81601714).

11. Alhamdi Y, Neill DR, Abrams ST, Malak HA, Yahya R, Barrett-Jolley R, et al. Circulating pneumolysin is a potent inducer of cardiac injury during pneumococcal infection. PLoS Pathog (2015) 11(5):e1004836. doi:10.1371/ journal.ppat.1004836

12. Hedayat M, Netea MG, Rezaei N. Targeting of toll-like receptors: a decade of progress in combating infectious diseases. Lancet Infect Dis (2011) 11(9):702-12. doi:10.1016/S1473-3099(11)70099-8

13. Zhang M, Zou L, Feng Y, Chen YJ, Zhou Q, Ichinose F, et al. Toll-like receptor 4 is essential to preserving cardiac function and survival in low-grade polymicrobial sepsis. Anesthesiology (2014) 121(6):1270-80. doi:10.1097/ aln.0000000000000337

14. Zou L, Feng Y, Chen YJ, Si R, Shen S, Zhou Q, et al. Toll-like receptor 2 plays a critical role in cardiac dysfunction during polymicrobial sepsis. Crit Care Med (2010) 38(5):1335-42. doi:10.1097/CCM.0b013e3181d99e67

15. Gao M, Ha T, Zhang X, Liu L, Wang X, Kelley J, et al. Toll-like receptor 3 plays a central role in cardiac dysfunction during polymicrobial sepsis. Crit Care Med (2012) 40(8):2390-9. doi:10.1097/CCM.0b013e3182535aeb

16. Gao M, Ha T, Zhang X, Wang X, Liu L, Kalbfleisch J, et al. The toll-like receptor 9 ligand, $\mathrm{CpG}$ oligodeoxynucleotide, attenuates cardiac dysfunction in polymicrobial sepsis, involving activation of both phosphoinositide 3 kinase/ Akt and extracellular-signal-related kinase signaling. J Infect Dis (2013) 207(9):1471-9. doi:10.1093/infdis/jit036

17. Opal SM, Laterre PF, Francois B, LaRosa SP, Angus DC, Mira JP, et al. Effect of eritoran, an antagonist of MD2-TLR4, on mortality in patients with severe sepsis: the ACCESS randomized trial. JAMA (2013) 309(11):1154-62. doi:10.1001/jama.2013.2194

18. Eichenholz PW, Eichacker PQ, Hoffman WD, Banks SM, ParrilloJE, Danner RL, et al. Tumor necrosis factor challenges in canines: patterns of cardiovascular dysfunction. Am J Physiol (1992) 263(3 Pt 2):H668-75.

19. Vincent JL, Bakker J, Marecaux G, Schandene L, Kahn RJ, Dupont E. Administration of anti-TNF antibody improves left ventricular function in septic shock patients. Results of a pilot study. Chest (1992) 101(3):810-5. doi:10.1378/chest.101.3.810

20. Pathan N, Franklin JL, Eleftherohorinou H, Wright VJ, Hemingway CA, Waddell SJ, et al. Myocardial depressant effects of interleukin 6 in 
meningococcal sepsis are regulated by p38 mitogen-activated protein kinase. Crit Care Med (2011) 39(7):1692-711. doi:10.1097/CCM.0b013e3182186d27

21. Xu J, Zhang X, Pelayo R, Monestier M, Ammollo CT, Semeraro F, et al. Extracellular histones are major mediators of death in sepsis. Nat Med (2009) 15(11):1318-21. doi:10.1038/nm.2053

22. Xu J, Zhang X, Monestier M, Esmon NL, Esmon CT. Extracellular histones are mediators of death through TLR2 and TLR4 in mouse fatal liver injury. J Immunol (2011) 187(5):2626-31. doi:10.4049/jimmunol.1003930

23. Alhamdi Y, Abrams ST, Cheng Z, Jing S, Su D, Liu Z, et al. Circulating histones are major mediators of cardiac injury in patients with sepsis. Crit Care Med (2015) 43(10):2094-103. doi:10.1097/ccm.0000000000001162

24. Kalbitz M, Grailer JJ, Fattahi F, Jajou L, Herron TJ, Campbell KF, et al. Role of extracellular histones in the cardiomyopathy of sepsis. FASEB J (2015) 29(5):2185-93. doi:10.1096/f.14-268730

25. Kregel KC. Heat shock proteins: modifying factors in physiological stress responses and acquired thermotolerance. J Appl Physiol (1985) (2002) 92(5):2177-86. doi:10.1152/japplphysiol.01267.2001

26. Chen HW, Hsu C, Lu TS, Wang SJ, Yang RC. Heat shock pretreatment prevents cardiac mitochondrial dysfunction during sepsis. Shock (2003) 20(3):274-9. doi:10.1097/00024382-200309000-00013

27. Wang X, Zingarelli B, O'Connor M, Zhang P, Adeyemo A, Kranias EG, et al. Overexpression of Hsp20 prevents endotoxin-induced myocardial dysfunction and apoptosis via inhibition of NF-kappaB activation. J Mol Cell Cardiol (2009) 47(3):382-90. doi:10.1016/j.yjmcc.2009.05.016

28. Zhou H, Qian J, Li C, Li J, Zhang X, Ding Z, et al. Attenuation of cardiac dysfunction by HSPA12B in endotoxin-induced sepsis in mice through a PI3Kdependent mechanism. Cardiovasc Res (2011) 89(1):109-18. doi:10.1093/cvr/ cvq268

29. Hsu JH, Yang RC, Lin SJ, Liou SF, Dai ZK, Yeh JL, et al. Exogenous heat shock cognate protein 70 pretreatment attenuates cardiac and hepatic dysfunction with associated anti-inflammatory responses in experimental septic shock. Shock (2014) 42(6):540-7. doi:10.1097/SHK.0000000000000254

30. Harris HE, Andersson U, Pisetsky DS. HMGB1: a multifunctional alarmin driving autoimmune and inflammatory disease. Nat Rev Rheumatol (2012) 8(4):195-202. doi:10.1038/nrrheum.2011.222

31. Huang LF, Yao YM, Dong N, Yu Y, He LX, Sheng ZY. Association of high mobility group box-1 protein levels with sepsis and outcome of severely burned patients. Cytokine (2011) 53(1):29-34. doi:10.1016/j.cyto.2010. 09.010

32. Xu H, Su Z, Wu J, Yang M, Penninger JM, Martin CM, et al. The alarmin cytokine, high mobility group box 1 , is produced by viable cardiomyocytes and mediates the lipopolysaccharide-induced myocardial dysfunction via a TLR4/phosphatidylinositol 3-kinase gamma pathway. J Immunol (2010) 184(3):1492-8. doi:10.4049/jimmunol.0902660

33. Zhang C, Mo M, Ding W, Liu W, Yan D, Deng J, et al. High-mobility group box 1 (HMGB1) impaired cardiac excitation-contraction coupling by enhancing the sarcoplasmic reticulum (SR) $\mathrm{Ca}(2+)$ leak through TLR4-ROS signaling in cardiomyocytes. J Mol Cell Cardiol (2014) 74:260-73. doi:10.1016/j. yjmcc.2014.06.003

34. van de Sandt AM, Windler R, Godecke A, Ohlig J, Zander S, Reinartz M, et al. Endothelial NOS (NOS3) impairs myocardial function in developing sepsis. Basic Res Cardiol (2013) 108(2):330. doi:10.1007/s00395-013-0330-8

35. Zanotti-Cavazzoni SL, Hollenberg SM. Cardiac dysfunction in severe sepsis and septic shock. Curr Opin Crit Care (2009) 15(5):392-7. doi:10.1097/ MCC.0b013e3283307a4e

36. Bohm M, Kirchmayr R, Gierschik P, Erdmann E. Increase of myocardial inhibitory G-proteins in catecholamine-refractory septic shock or in septic multiorgan failure. Am J Med (1995) 98(2):183-6. doi:10.1016/ S0002-9343(99)80402-1

37. Massion PB, Feron O, Dessy C, Balligand JL. Nitric oxide and cardiac function: ten years after, and continuing. Circ Res (2003) 93(5):388-98. doi:10.1161/01. RES.0000088351.58510.21

38. Pacher P, Beckman JS, Liaudet L. Nitric oxide and peroxynitrite in health and disease. Physiol Rev (2007) 87(1):315-424. doi:10.1152/physrev.00029. 2006

39. Xu C, Yi C, Wang H, Bruce IC, Xia Q. Mitochondrial nitric oxide synthase participates in septic shock myocardial depression by nitric oxide overproduction and mitochondrial permeability transition pore opening. Shock (2012) 37(1):110-5. doi:10.1097/SHK.0b013e3182391831
40. Ferdinandy P, Danial H, Ambrus I, Rothery RA, Schulz R. Peroxynitrite is a major contributor to cytokine-induced myocardial contractile failure. Circ Res (2000) 87(3):241-7. doi:10.1161/01.RES.87.3.241

41. Soriano FG, Nogueira AC, Caldini EG, Lins MH, Teixeira AC, Cappi SB, et al. Potential role of poly(adenosine 5'-diphosphate-ribose) polymerase activation in the pathogenesis of myocardial contractile dysfunction associated with human septic shock. Crit Care Med (2006) 34(4):1073-9. doi:10.1097/01. CCM.0000206470.47721.8D

42. Levy RJ, Vijayasarathy C, Raj NR, Avadhani NG, Deutschman CS. Competitive and noncompetitive inhibition of myocardial cytochrome $\mathrm{C}$ oxidase in sepsis. Shock (2004) 21(2):110-4. doi:10.1097/01.shk.0000108400.56565.ab

43. Wang F, Pan W, Wang H, Wang S, Pan S, Ge J. Relationship between thyroid function and ICU mortality: a prospective observation study. Crit Care (2012) 16(1):R11. doi:10.1186/cc11151

44. Galley HF. Oxidative stress and mitochondrial dysfunction in sepsis. $\mathrm{Br}$ J Anaesth (2011) 107(1):57-64. doi:10.1093/bja/aer093

45. Piel DA, Deutschman CS, Levy RJ. Exogenous cytochrome C restores myocardial cytochrome oxidase activity into the late phase of sepsis. Shock (2008) 29(5):612-6. doi:10.1097/SHK.0b013e318157e962

46. Flynn A, Chokkalingam Mani B, Mather PJ. Sepsis-induced cardiomyopathy: a review of pathophysiologic mechanisms. Heart Fail Rev (2010) 15(6):605-11. doi:10.1007/s10741-010-9176-4

47. Zaky A, Deem S, Bendjelid K, Treggiari MM. Characterization of cardiac dysfunction in sepsis: an ongoing challenge. Shock (2014) 41(1):12-24. doi:10.1097/shk.0000000000000065

48. Kakihana Y, Ito T, Nakahara M, Yamaguchi K, Yasuda T. Sepsis-induced myocardial dysfunction: pathophysiology and management. J Intensive Care (2016) 4:22. doi:10.1186/s40560-016-0148-1

49. Sharshar T, Annane D, de la Grandmaison GL, Brouland JP, Hopkinson NS, Francoise G. The neuropathology of septic shock. Brain Pathol (2004) 14(1):21-33. doi:10.1111/j.1750-3639.2004.tb00494.x

50. Hoyer D, Friedrich H, Zwiener U, Pompe B, Baranowski R, Werdan K, et al. Prognostic impact of autonomic information flow in multiple organ dysfunction syndrome patients. Int J Cardiol (2006) 108(3):359-69. doi:10.1016/j. ijcard.2005.05.031

51. Sharshar T, Gray F, Lorin de la Grandmaison G, Hopkinson NS, Ross E, Dorandeu A, et al. Apoptosis of neurons in cardiovascular autonomic centres triggered by inducible nitric oxide synthase after death from septic shock. Lancet (2003) 362(9398):1799-805. doi:10.1016/S0140-6736(03) 14899-4

52. Gholami M, Mazaheri P, Mohamadi A, Dehpour T, Safari F, Hajizadeh S, et al. Endotoxemia is associated with partial uncoupling of cardiac pacemaker from cholinergic neural control in rats. Shock (2012) 37(2):219-27. doi:10.1097/ SHK.0b013e318240b4be

53. Zorn-Pauly K, Pelzmann B, Lang P, Machler H, Schmidt H, Ebelt H, et al. Endotoxin impairs the human pacemaker current If. Shock (2007) 28(6):655-61.

54. Rudiger A, Singer M. Mechanisms of sepsis-induced cardiac dysfunction. Crit Care Med (2007) 35(6):1599-608. doi:10.1097/01.CCM.0000266683. 64081.02

55. Raeburn CD, Calkins CM, Zimmerman MA, Song Y, Ao L, Banerjee A, et al. Vascular cell adhesion molecule-1 expression is obligatory for endotoxin-induced myocardial neutrophil accumulation and contractile dysfunction. Surgery (2001) 130(2):319-25. doi:10.1067/msy.2001.116410

56. Tissier S, Lancel S, Marechal X, Mordon S, Depontieu F, Scherpereel A, et al. Calpain inhibitors improve myocardial dysfunction and inflammation induced by endotoxin in rats. Shock (2004) 21(4):352-7. doi:10.1097/ 00024382-200404000-00010

57. Furian T, Aguiar C, Prado K, Ribeiro RV, Becker L, Martinelli N, et al. Ventricular dysfunction and dilation in severe sepsis and septic shock: relation to endothelial function and mortality. JCrit Care (2012) 27(3):319.e9-15. doi:10.1016/j.jcrc.2011.06.017

58. Rhodes A, Evans LE, Alhazzani W, Levy MM, Antonelli M, Ferrer R, et al. Surviving Sepsis Campaign: International Guidelines for Management of Sepsis and Septic Shock: 2016. Crit Care Med (2017) 45(3):486-552. doi:10.1097/CCM.0000000000002255

59. Hogue B, Chagnon F, Lesur O. Resuscitation fluids and endotoxin-induced myocardial dysfunction: is selection a load-independent differential issue? Shock (2012) 38(3):307-13. doi:10.1097/SHK.0b013e31825e7ae9 
60. De Backer D, Biston P, Devriendt J, Madl C, Chochrad D, Aldecoa C, et al. Comparison of dopamine and norepinephrine in the treatment of shock. N Engl J Med (2010) 362(9):779-89. doi:10.1056/NEJMoa0907118

61. HasslacherJ, Bijuklic K, BertocchiC, KountchevJ, Bellmann R, Dunzendorfer S, et al. Levosimendan inhibits release of reactive oxygen species in polymorphonuclear leukocytes in vitro and in patients with acute heart failure and septic shock: a prospective observational study. Crit Care (2011) 15(4):R166. doi: $10.1186 / \mathrm{cc} 10307$

62. Gordon AC, Perkins GD, Singer M, McAuley DF, Orme RM, Santhakumaran S, et al. Levosimendan for the prevention of acute organ dysfunction in sepsis. N Engl J Med (2016) 375(17):1638-48. doi:10.1056/NEJMoa1609409

63. Arnold P, Lu X, Amirahmadi F, Brandl K, Arnold JM, Feng Q. Recombinant human annexin A5 inhibits proinflammatory response and improves cardiac function and survival in mice with endotoxemia. Crit Care Med (2014) 42(1):e32-41. doi:10.1097/CCM.0b013e3182a63e01

64. Drosatos K, Khan RS, Trent CM, Jiang H, Son NH, Blaner WS, et al. Peroxisome proliferator-activated receptor-gamma activation prevents sepsis-related cardiac dysfunction and mortality in mice. Circ Heart Fail (2013) 6(3):550-62. doi:10.1161/circheartfailure.112.000177

65. Zhou Q, Pan X, Wang L, Wang X, Xiong D. The protective role of neuregulin-1: a potential therapy for sepsis-induced cardiomyopathy. Eur J Pharmacol (2016) 788:234-40. doi:10.1016/j.ejphar.2016.06.042

66. Zhai J, Guo Y. Paeoniflorin attenuates cardiac dysfunction in endotoxemic mice via the inhibition of nuclear factor-kappaB. Biomed Pharmacother (2016) 80:200-6. doi:10.1016/j.biopha.2016.03.032

67. Smeding L, Leong-Poi H, Hu P, Shan Y, Haitsma JJ, Horvath E, et al. Salutary effect of resveratrol on sepsis-induced myocardial depression. Crit Care Med (2012) 40(6):1896-907. doi:10.1097/CCM.0b013e31824e1370

68. Liu YC, Yao FH, Chai YF, Dong N, Sheng ZY, Yao YM. Xuebijing injection promotes M2 polarization of macrophages and improves survival rate in septic mice. Evid Based Complement Alternat Med (2015) 2015:352642. doi:10.1155/2015/352642

69. DuanEH,OczkowskiSJ,Belley-CoteE, WhitlockR,LamontagneF,DevereauxPJ, et al. beta-Blockers in sepsis: protocol for a systematic review and meta-analysis of randomised control trials. BMJ Open (2016) 6(6):e012466. doi:10.1136/ bmjopen-2016-012466
70. Morelli A, Ertmer C, Westphal M, Rehberg S, Kampmeier T, Ligges S, et al. Effect of heart rate control with esmolol on hemodynamic and clinical outcomes in patients with septic shock: a randomized clinical trial. JAMA (2013) 310(16):1683-91. doi:10.1001/jama.2013.278477

71. Kimmoun A, Louis H, Al Kattani N, Delemazure J, Dessales N, Wei C, et al. beta1-adrenergic inhibition improves cardiac and vascular function in experimental septic shock. Crit Care Med (2015) 43(9):e332-40. doi:10.1097/ ccm.0000000000001078

72. Khan AI, Coldewey SM, Patel NS, Rogazzo M, Collino M, Yaqoob MM, et al. Erythropoietin attenuates cardiac dysfunction in experimental sepsis in mice via activation of the beta-common receptor. Dis Model Mech (2013) 6(4):1021-30. doi:10.1242/dmm.011908

73. Brines M, Patel NS, Villa P, Brines C, Mennini T, De Paola M, et al. Nonerythropoietic, tissue-protective peptides derived from the tertiary structure of erythropoietin. Proc Natl Acad Sci U S A (2008) 105(31):10925-30. doi:10.1073/pnas.0805594105

74. Gurha P. MicroRNAs in cardiovascular disease. Curr Opin Cardiol (2016) 31(3):249-54. doi:10.1097/HCO.0000000000000280

75. Gao M, Wang X, Zhang X, Ha T, Ma H, Liu L, et al. Attenuation of cardiac dysfunction in polymicrobial sepsis by microRNA-146a is mediated via targeting of IRAK1 and TRAF6 expression. J Immunol (2015) 195(2):672-82. doi:10.4049/jimmunol.1403155

76. Wang H, Bei Y, Shen S, Huang P, Shi J, Zhang J, et al. miR-21-3p controls sepsis-associated cardiac dysfunction via regulating SORBS2. J Mol Cell Cardiol (2016) 94:43-53. doi:10.1016/j.yjmcc.2016.03.014

Conflict of Interest Statement: The authors declare that the research was conducted in the absence of any commercial or financial relationships that could be construed as a potential conflict of interest.

Copyright (c) $2017 \mathrm{Liu}, \mathrm{Yu}$, Shou and Chai. This is an open-access article distributed under the terms of the Creative Commons Attribution License (CC BY). The use, distribution or reproduction in other forums is permitted, provided the original author(s) or licensor are credited and that the original publication in this journal is cited, in accordance with accepted academic practice. No use, distribution or reproduction is permitted which does not comply with these terms. 